\title{
Adaptação e análise de um laminador didático para metais não ferrosos
}

\author{
Adaptation and analysis of a didactic \\ laminator for non-ferrous metals
}

\author{
Mateus Willian Da Rosa ${ }^{1}$, Cláudia Trindade Oliveira ${ }^{1}$, \\ Fernando Dal Pont Morisso ${ }^{1}$, Sandra Raquel Kunst ${ }^{2}$, \\ Jane Zoppas Ferreira ${ }^{2}$, Josimar Souza Rosa ${ }^{1}$
}

\author{
${ }^{1}$ ICCT, Universidade Feevale, CEP: 239, 2755, Novo Hamburgo, Rio Grande do Sul, Brasil. \\ ${ }^{2}$ LACOR, Federal Universidade do Rio Grande do Sul, UFRGS, Avenida Bento Gonçalves, 9500, Porto Alegre, Rio \\ Grande do Sul, Brasil. \\ e-mail: mateuss.w@hotmail.com, cto@feevale.br, morisso@feevale.br, tessaro.sandra@gmail.com, \\ jane.zoppas@ufrgs.br, josimarrosa@feevale.br
}

\section{RESUMO}

A laminação é um processo de conformação por deformação plástica amplamente utilizado na indústria para o processamento de ligas metálicas semi-acabadas, pois, além de dar a forma comercial desejada ao produto, proporciona o aumento das propriedades mecânicas em um processo contínuo e de grande produtividade. Desta forma, é importante que o acadêmico de engenharia compreenda como funcionam os equipamentos utilizados na laminação e quais são as variáveis que influenciam este processo. Dentro deste contexto, e pensando que habilidades obtidas através de experimentos que relacionem a teoria com a prática são fundamentais para a formação de um engenheiro, a proposta deste trabalho foi projetar e adaptar um laminador didático do tipo $d u o$, para metais não ferrosos que, empregado no decorrer da graduação, promova maior proximidade dos alunos de engenharia com este processo industrial. A adaptação deste dispositivo se deu com base em um laminador de joias manual já existente, o qual foi acoplado a um motor elétrico que promovesse a potência necessária para o processo. O resultado deste trabalho foi a adaptação de um laminador que atendesse as expectativas de laminação, estando disponível para a elaboração de atividades que propulsionam o entendimento acadêmico sobre o tema. Em relação aos metais que foram laminados, diversas características do processo de laminação a frio e de seus produtos descritos pela literatura e pela indústria da transformação mecânica foram observadas durante a execução dos testes de funcionamento e dos ensaios, validando, desta forma, a adaptação do equipamento e o alcance de seu principal objetivo.

Palavras-chave: Laminação a frio. Conformação mecânica. Laminador $d u o$.

\begin{abstract}
Lamination is a plastic deformation forming process widely used in the industry for the processing of semifinished metal alloys, as it not only gives the desired commercial shape to the product, but also provides increased mechanical properties in a continuous and high productivity process. In this way, it is important that the engineering academic understand how the equipment used in the lamination works and what are the variables that influence this process. In this context, and thinking that skills obtained through experiments that relate theory to practice are fundamental for the formation of an engineer, the purpose of this work was to design and adapt a didactic laminator of the duo type, for nonferrous metals that, employee during the graduation, promote greater proximity of engineering students with this industrial process. The adaptation of this device was based on an existing manual jewelry mill, which was coupled to an electric motor that promoted the power needed for the process. The result of this work was the adaptation of a rolling mill that met the lamination expectations, being available for the elaboration of activities that propel the academic understanding on the subject. In relation to the metals that were rolled, several characteristics of the cold rolling process and its products described in the literature and in the mechanical transformation industry were observed during the execution of the tests of operation and of the tests, thus validating the adaptation of the equipment and the achievement of its main objective.
\end{abstract}

Keywords: Cold rolling. Metal forming. Duo laminator. 


\section{INTRODUÇÃO}

A utilização de metais para a construção de ferramentas e utensílios teve grande representação na história dos povos, tornando a vida do homem mais fácil e confortável. Com o aperfeiçoamento de técnicas de trabalho dos metais e a construção de fornos que atingiam maiores temperaturas, o homem aprendeu a moldar diversos tipos de metais conforme suas necessidades, auxiliando na caça, agricultura e até mesmo em guerras [1, 2].

A modelagem do metal ocorre através de deformações plásticas e proporciona mudanças em suas características mecânicas devido ao encruamento dos grãos, produzindo peças com excelentes propriedades e mínimas perdas de material, podendo acontecer em duas configurações de temperatura: à quente ou à frio. A conformação a quente apresenta como características grandes deformações, menores valores de força e pouca precisão. Neste tipo de deformação não há encruamento, pois, a conformação ocorre acima da temperatura de recristalização, portanto não há ganhos nas propriedades mecânicas. Em contrapartida, a laminação a frio trabalha com baixas deformações, altas forças e grandes precisões dimensionais, além de proporcionar o encruamento e melhora nas propriedades [3, 4].

Após sua obtenção, os metais passam por processos de conformação com a finalidade de obter medidas e formas pré-estabelecidas para o mercado. Uma das formas de conformação mais utilizadas é a laminação. Este processo consiste na passagem de um corpo entre dois cilindros que giram a distâncias menores que sua espessura, gerando uma tensão superficial capaz de deformar o material plasticamente [5, 6].

A laminação se mostra importante dentre os demais processos de conformação pois apresenta bom controle dimensional e elevada produtividade devido à sua continuidade. Segundo dados do Instituto Aço Brasil (2018) [7] a produção brasileira de aço bruto no período de setembro de 2017 a setembro de 2018 foi de 26,1 milhões de toneladas e de aços laminados foi de 17,5 milhões de toneladas, representando uma boa parcela frente aos demais processos.

Este processo, apesar de tão importante para o acadêmico de engenharia, costuma ser visto de forma teórica, sem ligação a estudos práticos, muitas vezes devido à falta de estrutura e equipamentos necessários. ANDRADE e MASSABNI [8] citam como fundamentais a execução de atividades práticas para o aprendizado. Segundo os autores, a elaboração de atividades práticas que envolvem os alunos estimula a elaboração e criação de hipóteses, de estratégias e de soluções para um problema, raciocínio e criação. Dentro deste contexto, e pensando que tais habilidades obtidas através de experimentos práticos são qualidades fundamentais de um engenheiro, a finalidade principal deste trabalho é adaptar um laminador didático de metais não ferros que, empregado no decorrer da graduação, promova maior proximidade dos alunos de engenharia sobre a teoria e a prática.

\section{MATERIAIS E MÉTODOS}

Para a elaboração deste trabalho foram utilizados materiais, equipamentos e instrumentos que proporcionassem a adaptação de um laminador de pequeno porte, tornando possível a realização da laminação de materiais não ferrosos.

\subsection{Caracterização dos materiais, do experimento e dos corpos de prova}

Para analisar o laminador foram realizados alguns ensaios experimentais com corpos de provas construídos com materiais não ferrosos, sendo estes em alumínio e latão. A escolha destes materiais se dá, principalmente, devido a sua característica de dureza ser inferior em elação aos materiais ferrosos. Desta forma, como não se tem os dados de projeto do laminador base, mas se sabe que foi desenvolvido para a laminação de materiais mais macios (ouro e prata) e possui rolos laminadores de aço, ao laminar materiais mais moles que o rolo, seu desgaste ocorre de forma menos crítica.

A fim de comprovar a funcionalidade do equipamento foram fabricados 15 corpos de provas que atendessem às expectativas de repetibilidade e funcionalidade. Os experimentos seguiram a seguinte ordem:

a. Laminação de 5 corpos de alumínio, 1 por vez, em uma etapa;

b. Laminação de 5 corpos de alumínio, 1 por vez, em duas etapas;

c. Laminação de 5 corpos de latão, 1 por vez, em duas etapas.

O latão não foi laminado em apenas uma etapa pois não proporcionou agarre com os cilindros de laminação. A matéria-prima destes materiais foi adquirida em formato cilíndrico (Figura 1-a), devendo ser usinada conforme as dimensões da Figura 1-b. Esta usinagem foi estabelecida a fim de proporcionar marcas na superfície e aumentar a rugosidade, desta forma, potencializando alguns resultados obtidos experimentalmente. 


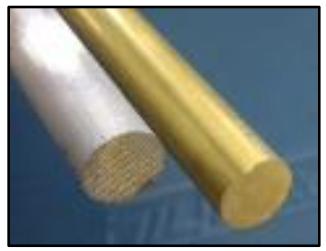

(a)

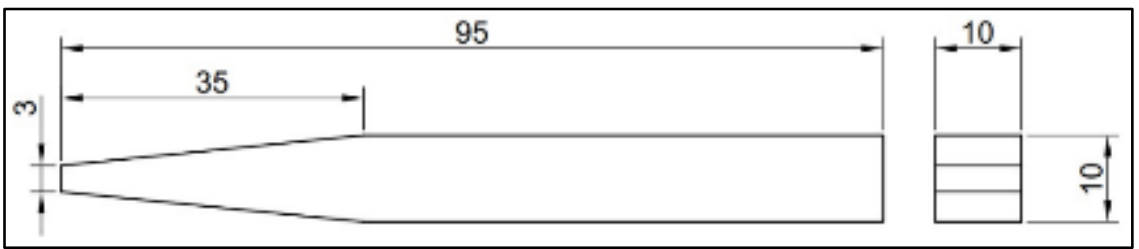

(b)

Figura 1: (a) forma da matéria-prima; (b) dimensões do corpo de prova usinado.

O formato da matéria-prima se dá pela sua maior facilidade de obtenção e também por permitir a usinagem dos corpos para as dimensões desejadas com a menor perda de material possível. As dimensões dos corpos de prova, estabelecidas conforme a Figura 1-b, foram escolhidas arbitrariamente. Destaca-se que, para que ocorresse o agarre, entre o corpo que se pretendia laminar e os rolos de laminação, foi previsto a usinagem de um chanfro na extremidade do corpo, conforme mostra a Figura 2-b. Foi utilizado a liga Al-Mg-Si, de especificação ASTM 6262E T6, sendo conhecida por sua boa usinabilidade aliado a alta resistência à corrosão. A liga de latão escolhida foi a ASTM-B-16 C360, comercialmente conhecida como latão corte livre americano, com têmpera 1/2 duro. Esta liga de latão é principalmente aplicada na produção em tornos automáticos de alta velocidade de corte, tais como: pinos, buchas e mancais. Apesar destas serem ligas utilizadas na indústria para processos de usinagem, não sendo ligas provindas de laminação, conseguem atender às expectativas de laminação e caracterização solicitadas para que seja possível realizar a análise experimental proposta. Os corpos de prova usinados são mostrados na Figura 2-a e 2-b.
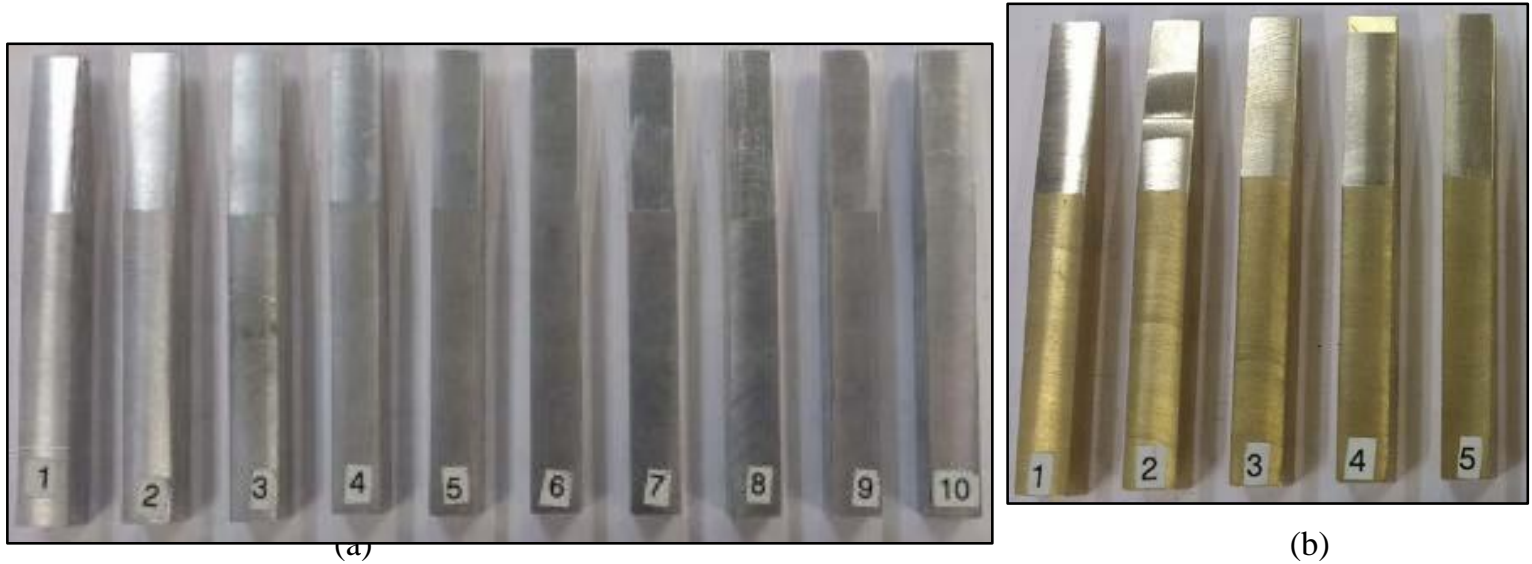

(b)

Figura 2: Corpos de prova (a) ASTM 6262E T6; (b) ASTM-B-16 C360 1/2 duro.

O processo de usinagem dos corpos de prova ocorreu em uma fresadora convencional, portanto, as dimensões estabelecidas na Figura 2-a e 2-b foram atendidas com um desvio aproximado de 0,2 mm, conforme será mostrado na seção de resultados. Ainda sobre a caracterização destas ligas, foi realizado ensaios de tração, conforme norma ASTM E8 / E8M - 09, a fim de se obter as curvas de escoamento convencionais, onde se considera a área de seção constante, tornando de conhecimento principal os valores de tensão de escoamento $\left(\sigma_{e}\right)$, tensão máxima $\left(\sigma_{m a ́ x}\right)$ e deformação $(\varepsilon)$. De posse destes dados é possível calcular a nova tensão de escoamento $K_{f l}$ (Equação 1) obtida em dado ponto devido ao encruamento em função da tensão máxima e da deformação relativa.

$K_{f 1}=\sigma_{m a ́ x} \cdot(1+\varepsilon)$

Para o ponto calculado conforme a Equação 1, sabe-se que na tensão máxima, a deformação verdadeira é igual ao coeficiente de encruamento, isto é, $\varphi=n$, portanto, ressaltando que esta igualdade vale apenas para o ponto de tensão máxima, podemos, através do método apresentado na literatura por SCHAEFFER [9], obter o coeficiente de encruamento $(C)$, conforme a Equação 2.

$$
C=\frac{K_{f 1}}{\varphi^{n}}
$$

Desta forma, pode-se reescrever a Equação 3 da seguinte forma: 
$K_{f 1}=C \cdot \varphi^{n}$

Onde é possível calcular o $K_{f 1}$ para qualquer deformação conhecida, sendo possível, portanto, obter as curvas de escoamento verdadeiras dos materiais e os novos valores de tensão de escoamento obtidas após o encruamento do ponto analisado. Outra característica analisada foi a dureza destas ligas antes e depois da laminação através de ensaios de dureza por penetração, realizados na escala Rockwell B. Para realização destes ensaios foi utilizado o penetrador com esfera de $1,59 \mathrm{~mm}$ de diâmetro e carga de $100 \mathrm{kgf}$, sendo estes parâmetros específicos para ligas de cobre, aços moles, ligas de alumínio ou ferro maleável [10].

A fim de analisar de forma qualitativa a máxima redução possível do equipamento, também foram realizados experimentos com outros 3 corpos de prova alternativos, distinguidos em CP A, CP B e CP C. Os corpos de prova A e B possuem o dimensional idêntico aos descritos na Figura 1-b, sendo das ligas de latão ASTM-B-16 C360 e alumínio ASTM 6262E T6, respectivamente. O corpo de prova C apresenta dimensões iniciais de 9,52 x 9,52 x $110 \mathrm{~mm}$ de uma liga de alumínio desconhecida.

\subsection{Caracterizações do laminador base}

Para a construção do laminador proposto para este trabalho, foram feitas adaptações em um laminador de joias manual da marca Menac. Este tipo de equipamento é muito utilizado na fabricação de joias, sendo específico para laminar metais não ferrosos como a prata e ouro. Devido a este já ser um equipamento pronto e não específico para exemplificar o processo produtivo de laminação, são encontradas algumas desvantagens como, por exemplo, a impossibilidade de utilizar um trem de rolos de laminação dispostos em série e também a falta de dados em relação aos materiais no qual ele é construído. Além disso, outras características de elementos de máquina já são impostas, obrigando o projeto a percorrer limites pré-estabelecidos.

$\mathrm{O}$ acionamento dos rolos laminadores era realizado de forma manual, por meio de uma alavanca que movimentava o sistema. Ao movimentar esta alavanca, impulsionava-se o sistema, transmitindo toque para os rolos superior e inferior através de uma redução construída por engrenagens cilíndricas helicoidais de 12 e 37 dentes, resultando em um aumento de 3,08 vezes do torque de entrada. Conforme NIEMANN [11], este tipo de transmissão costuma ter um rendimento entre $96 \%$ e $99 \%$ para cada engrenagem helicoidal. Este equipamento também permite que, através de fusos e um volante, o afastamento entre os rolos seja ajustado permitindo a laminação de diferentes espessuras.

Os rolos laminadores dispostos horizontalmente são classificados conforme a literatura como sendo do tipo duo. A estrutura lateral do laminador é construída em chapa de aço de $3 / 4$ polegadas de espessura soldadas paralelamente. Os rolos de laminação são feitos em aço polido e possuem $48 \mathrm{~mm}$ de diâmetro, com largura útil de $110 \mathrm{~mm}$. O rolo inferior é mancalizado na estrutura, enquanto os superiores em mancais móveis de latão.

\subsection{Caracterização do motor e potência}

Para fornecer potência ao sistema, foi utilizado um motor do tipo indução trifásico da marca WEG de $0,5 \mathrm{cv}$ ligado em estrela com alimentação à tensão de linha de $220 \mathrm{~V}$. Conforme o fabricante, este tipo de motor é o mais usado, pois combina as vantagens da utilização de energia elétrica com sua construção simples e grande versatilidade de adaptação às cargas dos mais diversos tipos e melhores rendimentos. A potência deste motor foi definida a partir da máxima potência de entrada permitida pelo motoredutor, apresentado na seção seguinte. As informações técnicas do motor, conforme encontrado em sua placa de identificação, são descritas conforme a Tabela 1.

Tabela 1: Especificações da placa do motor

\begin{tabular}{lc}
\multicolumn{1}{c}{ Características } & Especificações \\
\hline Modelo & 71682 \\
Potência & $0,5 \mathrm{cv}$ \\
Tensão & $220 / 380 \mathrm{~V}$ \\
Corrente com ligação estrela/ triângulo & $2,2 / 1,2 \mathrm{~A}$ \\
Rotação & $1720 \mathrm{RPM}$ \\
Frequência & $60 \mathrm{~Hz}$ \\
Isolamento & $\mathrm{B}$ \\
\hline
\end{tabular}

De posse dos dados apresentados na Tabela 1 é possível realizar cálculos comparativos entre a potência teórica que será requerida pela laminação com a potência medida durante os experimentos. Conforme Cotrim 
[12], o cálculo da potência ativa total para sistemas trifásicos deve ser feito conforme Equação 4.

$$
P=\sqrt{3} \cdot U \cdot I \cdot \cos \varphi_{d}
$$

Portanto, a potência ativa total será dada pela tensão de linha $(U)$ multiplicada pela variação da corrente no momento da laminação $(I)$ e pelo cosseno do ângulo de defasagem $\left(\varphi_{d}\right)$ entre a tensão e a corrente de fase, também conhecido como fator de potência. Conforme o fabricante WEG [13], para esta categoria de motor operando em $100 \%$ de carga o fator de potência é 0,72 . Ainda se deve levar em consideração a eficiência do motor que, conforme o fabricante, é de aproximadamente $70 \%$.

\subsection{Caracterização do motoredutor}

Motoredutores são amplamente utilizados em projetos mecânicos onde há a necessidade de aumentar o torque de saída do sistema e em contrapartida diminuir sua velocidade de rotação. Estes equipamentos são usualmente fabricados em caixas vedadas de alumínio ou ferro fundido, onde engrenagens movidas por um parafuso sem-fim e mergulhadas em óleo lubrificante fazem a redução de velocidade e ampliação do toque.

Desta maneira, devido a laminação de metais exigir do sistema um valor de torque expressivamente maior do que o nominal oferecido pelo motor escolhido, foi utilizado um motoredutor que proporcionasse uma redução de velocidade e um aumento proporcional no torque disponível para os rolos laminadores. Para tanto, o modelo de motoredutor utilizado foi o QDR 754, da marca IBR, conforme mostra a Figura 3.

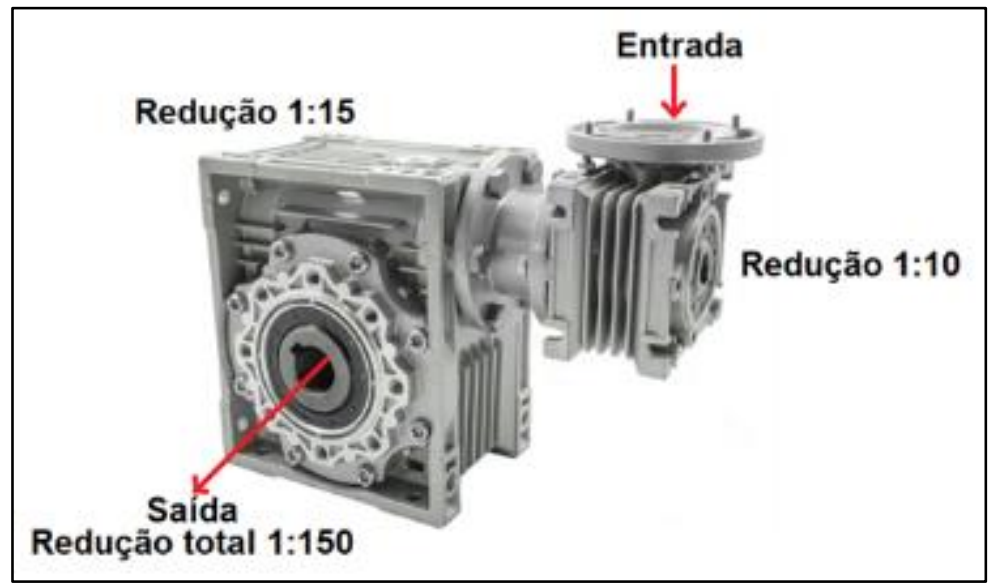

Figura 3: 1 Redutor IBR QDR 754 1:150.

Este motoredutor, conforme mostra a Figura 3, conta com dois estágios de redução, sendo o primeiro com redução de 1:10 e o segundo com redução de 1:15, totalizando uma redução de velocidades de 1:150. Na prática isso quer dizer que, para cada volta no eixo de saída do redutor o motor terá dado 150 voltas, gerando um aumento proporcional de 150 vezes do torque gerado na entrada. A tabela 2 demonstra os valores especificados para o redutor conforme dados retirados do catálogo comercial do fabricante, onde recomenda-se o uso com motores de potência máxima de $0,5 \mathrm{cv}$.

Tabela 2: Dados técnicos do motoredutor QDR 754.

\begin{tabular}{lc}
\hline Especificação & Valor \\
\hline Redução & 150 \\
Rotação de saída [RPM] & 11,33 \\
$P_{\text {mot }}[\mathrm{cv}]$ & 0,5 \\
$T_{\text {máx }}[\mathrm{Nm}]$ & 240,0 \\
Fator de serviço & 1 \\
$T_{\text {nom }}[\mathrm{Nm}]$ & 226,1 \\
$\mathrm{n}[\%]$ & 73,10 \\
\hline
\end{tabular}

Conforme dados apresentados na Tabela 2, o fabricante considerou na entrada do motoredutor uma potência $\left(\mathrm{P}_{\mathrm{mot}}\right)$ de $0,5 \mathrm{cv}$ e 1700 rotações por minuto $(\mathrm{RPM})$, onde o torque nominal $\left(T_{\text {nom }}\right)$ máximo no eixo de saída será de $240 \mathrm{Nm}$. Para as condições de mais de 10 partidas por hora, uso de cargas uniformes e menos de duas horas de operação por dia, o fator de serviço definido é de 1, portanto, o valor do torque máximo 
( $T_{\text {máx }}$ ) é o mesmo que o nominal. O mesmo acontece para a potência. O rendimento $(n)$ deste redutor, considerando os dois estágios, é de 73,10\%.

\subsection{Caracterização dos instrumentos}

Para realizar a análise e construção do equipamento, foram utilizados alguns instrumentos de medição. O paquímetro modelo CD-6"CSX-B da marca Mitutoyo com resolução de 0,01 mm e exatidão de $\pm 0,02 \mathrm{~mm}$ utilizado para a aferição das medidas iniciais e finais dos corpos de prova.

O durômetro modelo RASN-B da marca Pantec com resolução de 1 HR, utilizado na medição da dureza, onde é medida a profundidade da impressão deixada no material em questão. Para o experimento, este equipamento foi utilizado para medir a diferença de dureza dos corpos de prova antes e depois da laminação.

Para a medição da corrente elétrica exigida pelo motor foi utilizado um alicate amperímetro digital modelo ET-3200B da marca Minipa, com precisão de $\pm 3 \%$. Este modelo possui como característica a capacidade de medir elevados valores de corrente alternada utilizando o princípio da indução magnética e, portanto, proporcionando maior segurança ao usuário e resultados mais precisos. Além disso, foi utilizado um rugosímetro modelo M1 da marca Mahr com resolução de 12 ๆm, utilizado para determinar e registrar a rugosidade dos corpos de prova antes e depois da laminação através de parâmetros determinados (Ra, Rz, Rmax, e RPc). $O$ registro do perfil de rugosidade da superfície ainda pode ser impresso na impressora térmica embutida.

\subsection{Cálculo da potência de laminação}

Durante a análise do laminador, foram utilizadas metodologias que tornassem de conhecimento a potência necessária para realizar a conformação a frio dos corpos de prova. A sequência de cálculo definida foi embasada pelos autores SCHAEFFER [14] e HOSFORD [15] considerando um processo sem nenhum esforço auxiliar, empurrando ou puxando a chapa, conforme a Equação 5.

$\sigma_{m}=\frac{h_{m}}{\mu \cdot L} \cdot\left(\exp \frac{\mu \cdot L}{h_{m}}-1\right) \cdot\left(k_{f m}\right)$

Desta forma, a tensão média calculada estará conforme os parâmetros de laminação utilizados experimentalmente. O coeficiente de atrito $(\mu)$ utilizado no desenvolvimento dos cálculos foi de 0,1 que, conforme HELMAN [6] este resultado é conveniente para laminação de $\mathrm{Al}, \mathrm{Cu}$ e $\mathrm{Pb}$ utilizando cilindros de aço polido. Com o valor da tensão média obtido usando-se a Equação 5 e as variáveis geométricas do processo, pode-se calcular a potência de laminação.

\section{RESULTADOS E DISCUSSÃO}

\subsection{Análise e adaptação do laminador}

Para fazer a interação entre o motor, redutor e laminador, foi construído um modelo tridimensional, conforme apresentado na Figura 4. A modelagem do motor, motoredutor e laminador ocorreu através de análises dimensionais realizadas nos componentes existentes. Os demais itens foram desenvolvidos através das necessidades observadas para o projeto.

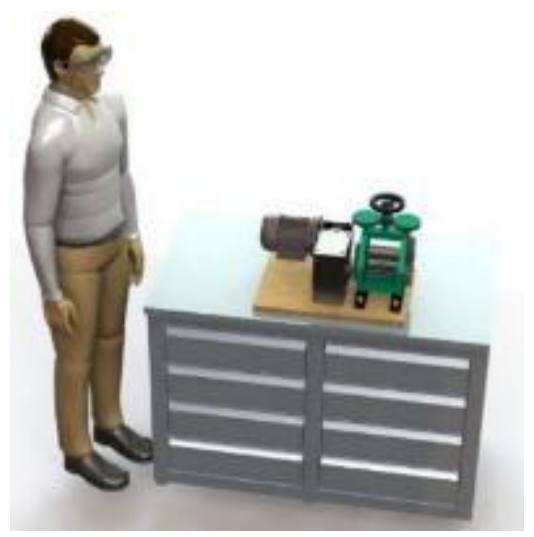

Figura 4: Detalhe para dimensão do laminador. 2

Conforme observado, a ideia inicial do trabalho previu que o equipamento fosse de pequena proporção, sendo usual em bancadas. A Figura 5 apresenta mais detalhadamente alguns elementos do laminador. 


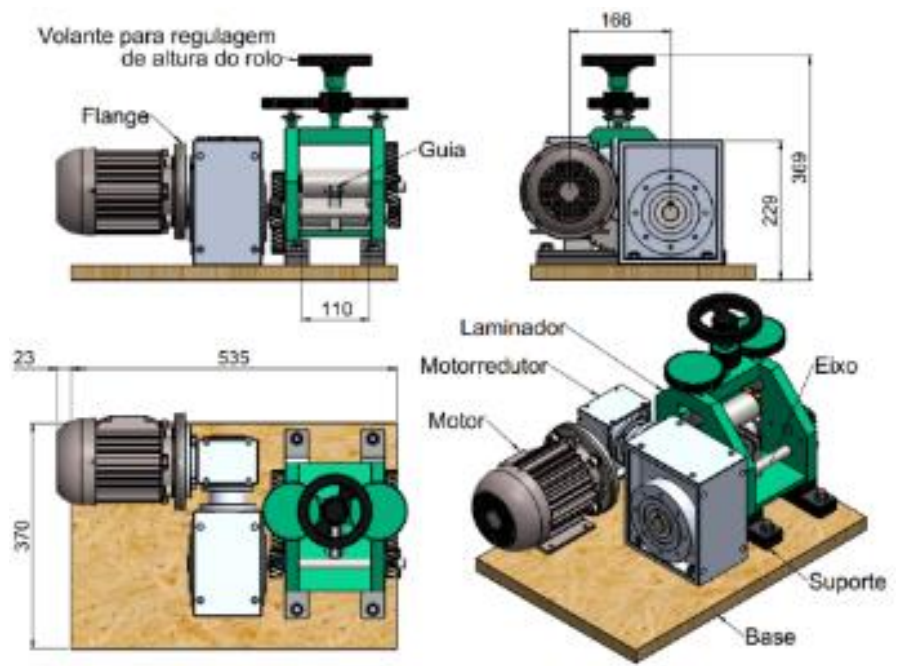

Figura 5: Modelo tridimensional do laminador.

A Figura 6 destaca os demais componentes do equipamento.

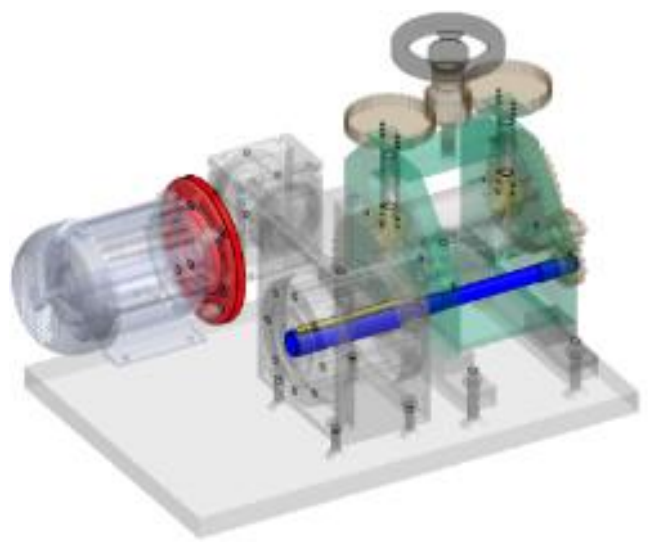

Figura 6: Destaque do flange e eixo desenhados.

Com o modelamento tridimensional, foram definidos os demais componentes do projeto. Nesta etapa, além do guia de laminação dos corpos de prova e da base construída em MDF, destacados na Figura 5, foram projetados um flange de acoplamento do motor-motoredutor e o eixo de transmissão, responsável por transmitir o torque de saída do redutor para as engrenagens cilíndricas helicoidais ligadas aos rolos de laminação. O flange, destacado em vermelho na Figura 6, foi fabricado em aço ASTM A-36, onde a matéria-prima foi comprada já em formato de disco com espessura de 5/8". Para transmitir a potência para o laminador a alavanca utilizada inicialmente foi retirada, sendo projetado um eixo de aço SAE 1045, destacado em azul na Figura 6. Nesta etapa também foram previstas e dimensionadas as chavetas necessárias para fazer o acoplamento entre os elementos de máquina. Esta etapa também foi importante para determinar a elevação vertical que deveria existir para que o centro do eixo do motoredutor coincidisse com o centro do eixo do laminador. A construção e montagem ocorreu, de forma geral, conforme o estipulado pelo modelo inicial. Foram realizadas adaptações no suporte (ver Figura 5), que passou a ser construído em MDF devido a facilidade de construção, sem oferecer risco ao projeto. A caixa de redução e o laminador foram fixados na base e no suporte através de parafusos sextavados internos. A Figura 7 apresenta o laminador didático construído.

Durante a montagem do equipamento se observou que a válvula de respiro, responsável pela saída de alívio de pressões internas, do primeiro estágio ficou voltada para baixo. Desta forma, durante o período de operação, ocorre o vazamento de uma pequena quantia de óleo, tornando necessário sua reposição antecipada. Tal detalhe não foi levado em consideração durante a análise do modelo tridimensional pois este componente não foi modelado no corpo do motoredutor. 


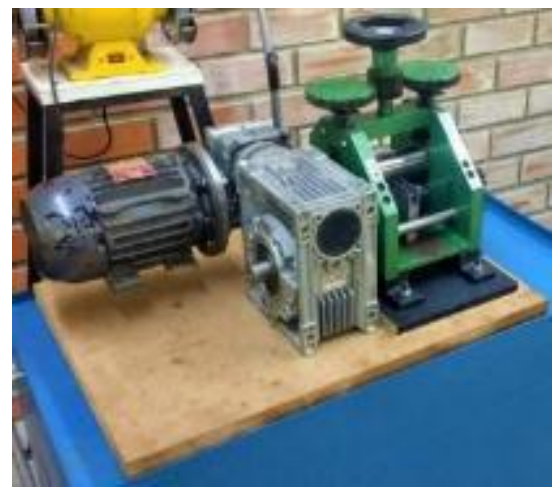

Figura 7: Laminador didático construído.

\subsection{Curva de tensão e deformação}

Foram realizados 4 ensaios de tração para cada liga laminada a fim de descobrir suas respectivas tensões de escoamento e deformações. Estes dados são importantes para a realização dos ensaios pois estão diretamente ligados à força de laminação requerida. Os resultados de tração para a liga de alumínio ASTM 6262E T6 são apresentados conforme a Figura 8.

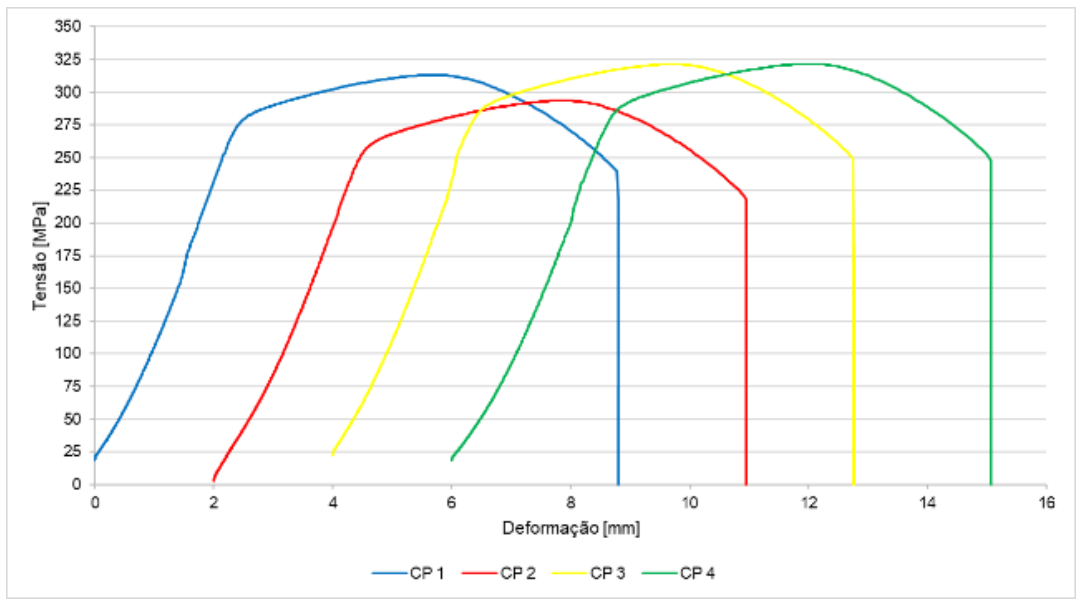

Figura 8: Gráfico Tensão x Deformação liga ASTM 6262E T6.

Conforme o resultado das curvas apresentadas na Figura 8, os principais resultados médios encontrados, pertinentes ao cálculo de potência de laminação, foram: tensão de escoamento $\left(\sigma_{e}\right)$ de $285,0 \mathrm{MPa}$, tensão máxima de ruptura $\left(\sigma_{u}\right)$ de $312,6 \mathrm{MPa}$ e deformação $(\varepsilon)$ na tensão máxima de $5,8 \mathrm{~mm}$. Os resultados encontrados estão coerentes com o certificado de matéria prima deste material, obedecendo os valores mínimos estipulados. Os resultados de tração para a liga de latão ASTM-B-16 C360 com têmpera 1/2 duro são apresentados conforme a Figura 9.

Conforme o resultado das curvas apresentadas na Figura 9, os principais resultados médios encontrados, pertinentes ao cálculo de potência de laminação, foram: tensão de escoamento $\left(\sigma_{e}\right)$ de $368,0 \mathrm{MPa}$, tensão máxima de ruptura $\left(\sigma_{u}\right)$ de $415,6 \mathrm{MPa}$ e deformação $(\varepsilon)$ na tensão máxima de $8,45 \mathrm{~mm}$. Os resultados encontrados para a tensão de escoamento estão coerentes com o certificado de matéria prima deste material. Entretanto, os valores de tensão máxima encontrados estão abaixo dos limites estabelecidos pelo certificado. Pode-se associar este fato a possível divergência entre o material solicitado e o entregue pelo vendedor. 


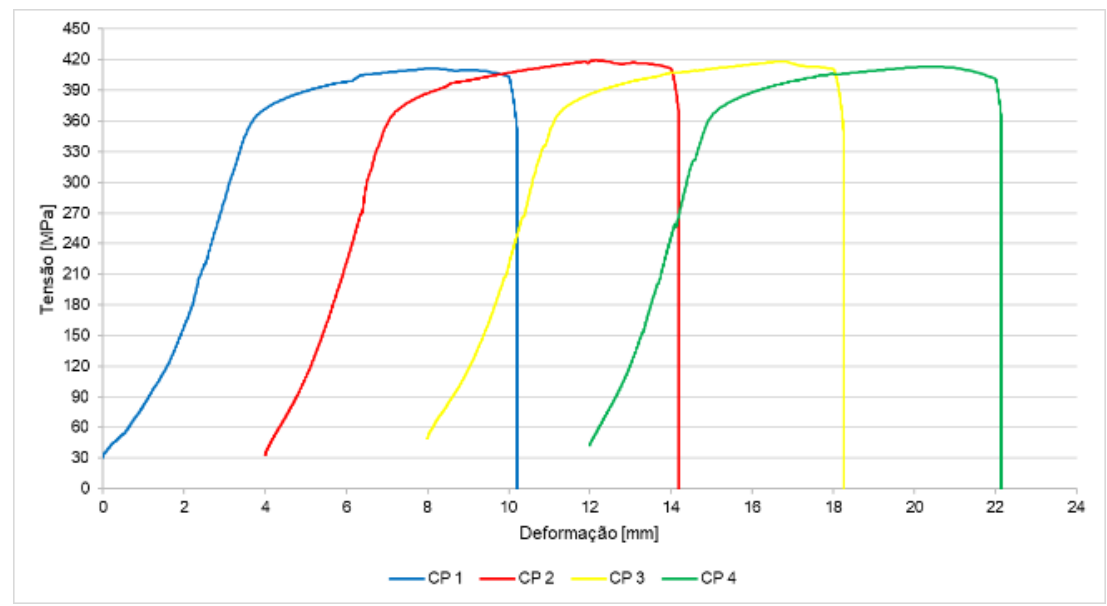

Figura 9: Gráfico Tensão x Deformação liga ASTM-B-16 C360 1/2 duro.

Através dos resultados dos ensaios de tração é de fundamental importância que seja analisado o limite imposto pelo coeficiente de estricção $(\phi)$ frente a intensidade de deformação na seção transversal $(\varphi)$ a fim de confirmar a viabilidade do processo, evitando rupturas [16]. Foram analisados os seguintes resultados, conforme a Tabela 3.

Tabela 3: Resultados de estricção.

\begin{tabular}{|c|c|c|}
\hline Material & Coeficiente de estricção [ $\phi]$ & Intensidade de deformação $[\varphi]$ \\
\hline Alumínio & 0,171 & 0,484 \\
\hline Latão & 0,168 & 0,448 \\
\hline
\end{tabular}

Conforme observado, os coeficientes de estricção ficaram abaixo do valor de intensidade de deformação, sendo o processo de conformação que reduzirá a seção em aproximadamente 1,70 mm, viável. Para os corpos A, B e C ressalta-se que esta regra não deve ser atingida, tendo em vista que a redução de espessura será a maior possível para o laminador.

\subsection{Análises dimensionais}

Conforme o esperado, a laminação a frio proporcionou alterações dimensionais nos corpos de prova laminados. As dimensões $b$ e $l$, conforme a Figura 10, tiveram aumento enquanto a dimensão $h$ diminuiu, da mesma forma que prevê a lei da constância do volume.
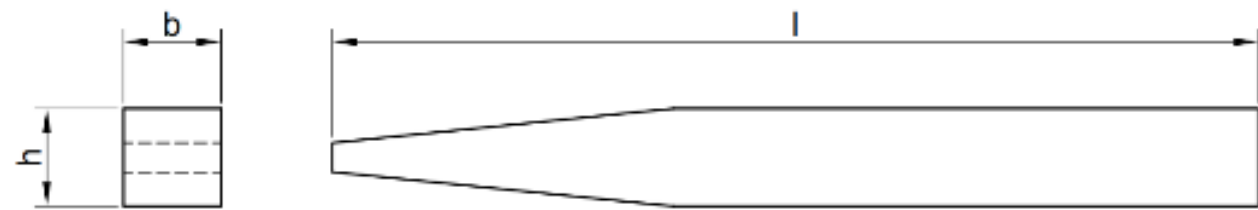

Figura 10:3 Representação das dimensões.

Ainda conforme a Figura 10, os valores dimensionais dos corpos de prova usinados e após passarem pela laminação são apresentados na Tabela 4. Os valores do chanfro não são apresentados pois são irrelevantes para os resultados analisados. 
Tabela 4: Laminação do alumínio em dois passes.

\begin{tabular}{ccccccc}
\hline $\begin{array}{c}\text { Corpo de prova } \\
\text { laminado }\end{array}$ & \multicolumn{2}{c}{ Dimensão inicial $\mathbf{m m}]$} & \multicolumn{3}{c}{ Dimensão final [mm] } \\
\hline hi & bi & li & hf & bf & If \\
\hline Primeiro passe & 9,90 & 9,93 & 94,87 & 9,06 & 10,28 & 99,47 \\
1 & 9,91 & 9,91 & 94,77 & 9,07 & 10,30 & 99,64 \\
2 & 9,91 & 9,95 & 94,65 & 9,07 & 10,28 & 99,61 \\
3 & 9,90 & 9,91 & 95,26 & 9,07 & 10,28 & 99,34 \\
5 & 9,91 & 9,90 & 94,83 & 9,07 & 10,31 & 99,55 \\
Média & 9,91 & 9,92 & 94,88 & 9,07 & 10,29 & 99,52 \\
Segundo passe & & & & & & \\
1 & 9,06 & 10,28 & 99,47 & 8,20 & 10,59 & 106,62 \\
2 & 9,07 & 10,30 & 99,64 & 8,20 & 10,57 & 106,21 \\
3 & 9,07 & 10,28 & 99,61 & 8,20 & 10,56 & 106,29 \\
4 & 9,07 & 10,28 & 99,34 & 8,20 & 10,56 & 106,52 \\
5 & 9,07 & 10,31 & 99,55 & 8,20 & 10,58 & 106,03 \\
Média & 9,07 & 10,29 & 99,52 & 8,20 & 10,57 & 106,33 \\
\hline
\end{tabular}

Conforme a Tabela 4, nota-se que os valores da dimensão $h_{f}$ se mantiveram bastante semelhantes em comparação as demais medidas. Como esperado, isto acontece divido a característica do processo de laminação a frio, onde tolerâncias dimensionais são menores e mais precisas. A Figura 11 apresenta os corpos após a laminação.

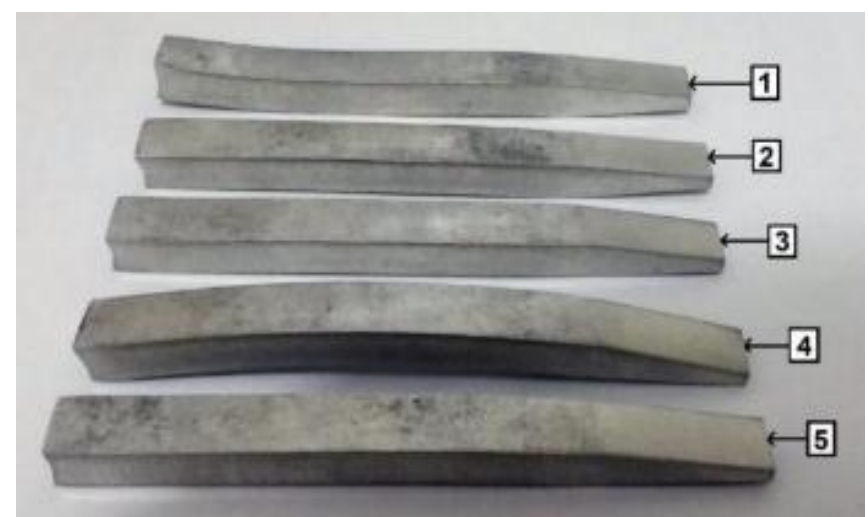

Figura 11: Corpos de alumínio laminados em dois passes.

A Tabela 5 apresenta os resultados de laminação do alumínio em um único passe.

Tabela 5: Laminação do alumínio em uma etapa.

\begin{tabular}{ccccccc}
\hline $\begin{array}{c}\text { Corpo de prova } \\
\text { laminado }\end{array}$ & \multicolumn{3}{c}{ Dimensão inicial [mm] } & \multicolumn{3}{c}{ Dimensão final [mm] } \\
hi & hínico passe & bi & li & hf & bf & If \\
\hline 6 & 9,91 & 9,92 & 94,80 & 8,05 & 10,55 & - \\
7 & 9,93 & 9,90 & 94,84 & 8,22 & 10,47 & 105,55 \\
8 & 10,12 & 10,05 & 94,90 & 8,22 & 10,74 & 106,33 \\
9 & 9,90 & 9,93 & 94,60 & 8,22 & 10,41 & 106,03 \\
10 & 9,92 & 9,89 & 94,90 & 8,22 & 10,39 & 105,85 \\
Média & 9,96 & 9,94 & 94,81 & 8,19 & 10,51 & 105,94 \\
\hline
\end{tabular}

Os resultados apresentados na Tabela 5 sugerem características semelhantes aos corpos de alumínio la- 
minados em duas etapas. Se observa que, mesmo para o corpo de prova número 8 , que possuía dimensões iniciais $h_{i}$ com maior desvio, seus resultados para a dimensão $h_{f}$ foram bastante semelhantes. $O$ corpo número 6, conforme apresenta a Figura 12, não foi possível fazer a laminação por completo devido a intensa diminuição de seção, causando resultados inconclusivos para este corpo.

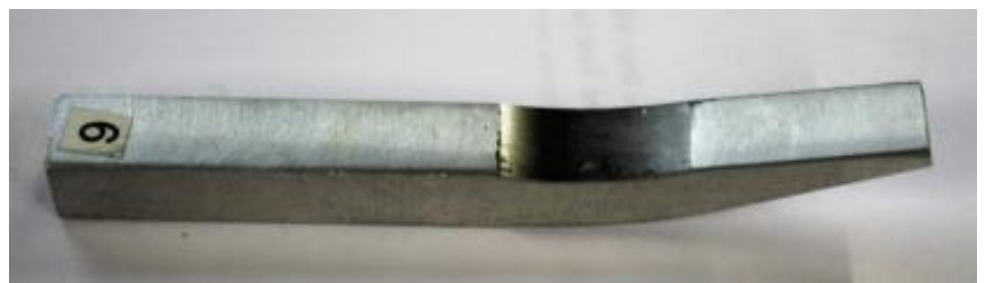

Figura 124: Corpo de prova 6 em alumínio laminado.

Conforme detalha a Figura 12, o corpo de prova 6 não foi laminado completamente, sendo possível visualizar a diferença na dimensão $h$ e também a visível melhora no acabamento superficial. O resultado de laminação deste corpo pode estar associado também com a contradição da relação apresentada na condição $t g$ $\alpha<\mu$, onde deveria ser obedecida para que se obtenha o ângulo de agarre necessário. De modo geral, os corpos de prova laminados em uma etapa tiveram deformações aleatórias maiores que o primeiro experimento, conforme mostra a Figura 13

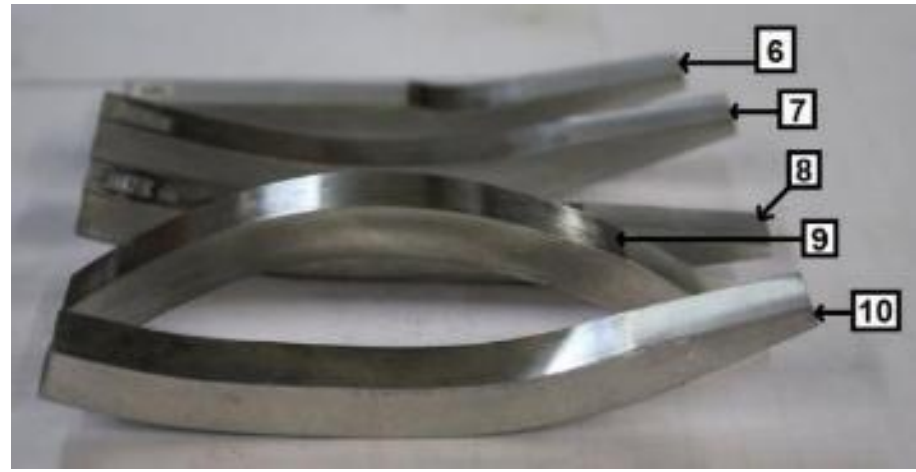

Figura 13: Corpos de alumínio laminados em um passe.

Os efeitos de deformação vistos na Figura 13, com destaque para o corpo de prova 9, acontece devido ao encruamento massivo que ocorre em função da grande diminuição de seção. A Tabela 6 apresenta os resultados de laminação para os corpos de prova de latão.

Tabela 6: Laminação do latão em duas etapas.

\begin{tabular}{ccccccc}
\hline $\begin{array}{c}\text { Corpo de prova } \\
\text { laminado }\end{array}$ & \multicolumn{3}{c}{ Dimensão inicial } & \multicolumn{3}{c}{ Dimensão final } \\
\hline Primeiro passe & & bi & li & hf & bf & If \\
1 & 9,94 & 9,97 & 94,96 & 9,31 & 10,26 & 98,15 \\
2 & 9,93 & 9,95 & 94,74 & 9,31 & 10,24 & 98,17 \\
3 & 9,95 & 9,96 & 94,9 & 9,32 & 10,26 & 98,33 \\
4 & 9,94 & 9,98 & 94,85 & 9,32 & 10,26 & 98,24 \\
5 & 9,97 & 9,97 & 94,89 & 9,32 & 10,27 & 98,39 \\
Média & 9,95 & 9,97 & 94,87 & 9,32 & 10,26 & 98,26 \\
Segundo passe & & & & & & \\
1 & 9,31 & 10,26 & 98,15 & 8,28 & 10,62 & 104,83 \\
2 & 9,31 & 10,24 & 98,17 & 8,28 & 10,63 & 105,19 \\
3 & 9,32 & 10,26 & 98,33 & 8,28 & 10,61 & 105,59 \\
4 & 9,32 & 10,26 & 98,24 & 8,27 & 10,61 & 105,55 \\
5 & 9,32 & 10,27 & 98,39 & 8,27 & 10,6 & 105,65 \\
Média & 9,32 & 10,26 & 98,26 & 8,28 & 10,61 & 105,36 \\
\hline
\end{tabular}

Os resultados da laminação do latão, conforme a Tabela 6, apresentam também resultados dimensionais 
bastante semelhantes aos vistos nas deformações do alumínio. Nestes corpos se observou o escorregamento entre as faces superior e inferior do corpo e os rolos nos primeiros instantes da laminação, associado ao baixo fator de atrito, da mesma forma que citado pela literatura [17, 18], impedindo que o material seja puxado pelos cilindros. A Figura 14 apresenta os corpos de latão após a laminação.

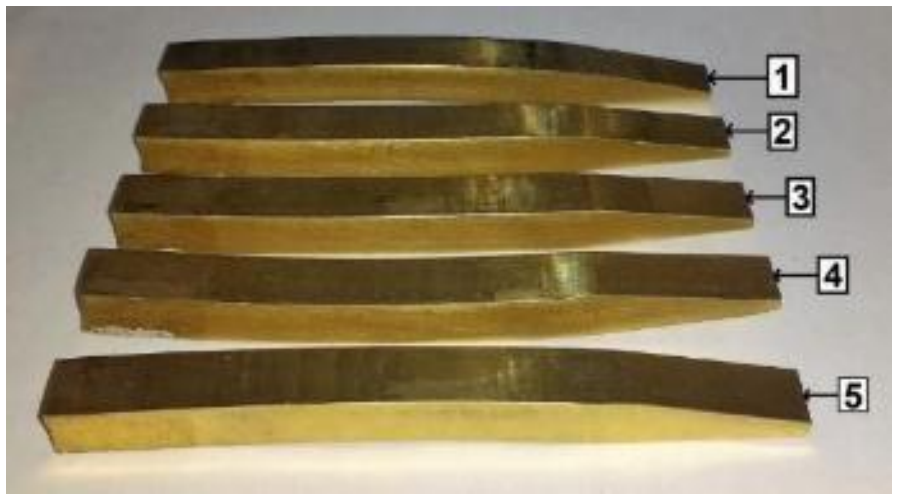

Figura 14: Corpos de latão laminados em dois passes.

Observa-se que os resultados finais da dimensão $h_{f}$ ficaram $0,08 \mathrm{~mm}$ maiores do que os de alumínio laminados em duas etapas. Isto está associado aos esforços causados nos rolos laminadores que, por serem maiores para este material devido a sua resistência mecânica superior, fazem com que os rolos tendam a sofrer maiores esforços fletores, causando maior variação geométrica em relação aos resultados anteriores. Tal efeito também pode ser observado entre a laminação dos corpos de alumínio, onde os corpos laminados em uma etapa tiveram uma diferença de espessura de $0,02 \mathrm{~mm}$ em relação aos laminados em duas etapas.

Para os corpos de prova A, B e C, onde a proposta experimental era de lamina-los laminados até a máxima redução possível, foram encontrados os seguintes resultados: o corpo A passou de 9,9 mm para 4,38 $\mathrm{mm}$, o corpo B passou de 9,9 mm para 1,30 mm e o corpo C passou de 9,52 mm para 5,68 mm. Os corpos de prova A, B e C são mostrados conforme a Figura 15-a, 15-b e 15-c, respectivamente.

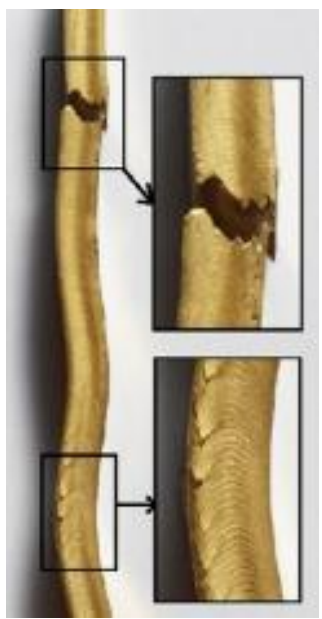

(a)

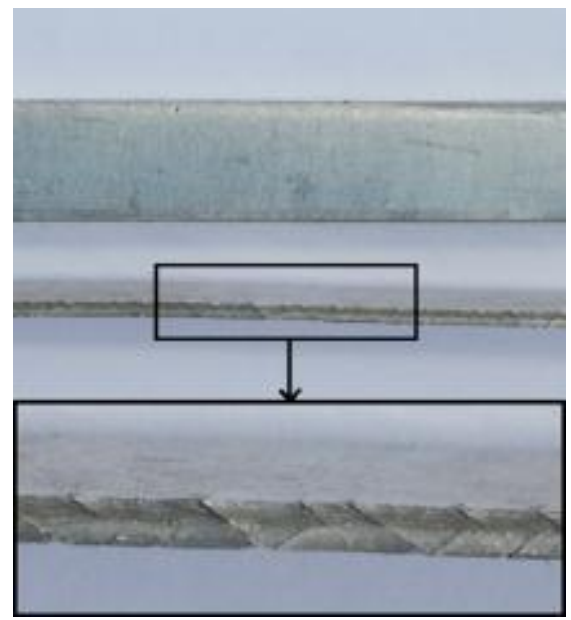

(b)

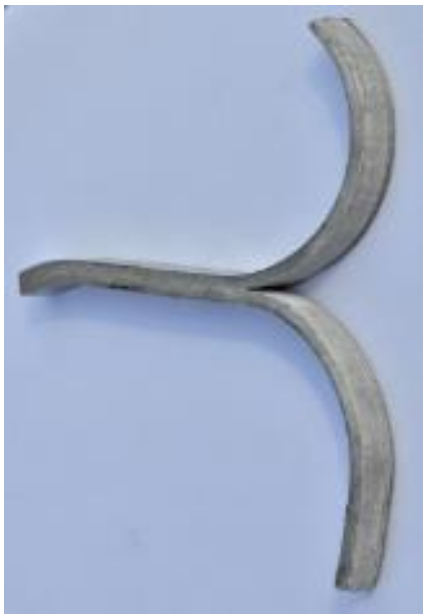

(c)

Figura 15: Corpo laminado (a) A; (b) B; (c) C.

O corpo A (Figura 15-a) apresentou ruptura na espessura 4,38 mm. Durante o experimento, após o corpo ter se contorcido na saída da laminação e já apresentar trincas, se tentou deforma-lo na direção contrária, a fim de deixa-lo em condições para um novo passe. Porém, tal ação incidiu no rompimento do corpo devido ao demasiado encruamento sofrido. O corpo B (Figura 15-b) apresentou um excelente resultado de laminação, onde seu comprimento passou de $95 \mathrm{~mm}$ para $615 \mathrm{~mm}$. As bordas laterais do corpo apresentaram um aspecto serrilhado, devido ao aparecimento de trincas a $45^{\circ}$ do sentido de laminação. Para os corpos A e B estas trincas foram bastante visíveis. Em ambos os casos, para as espessuras finais atingidas, a regra de estricção $\phi<\varphi$ não mais estava sendo respeitada, estando os corpos sujeitos a fratura eminente. Estima-se também que as marcas de usinagem deixadas nestes corpos, principalmente como visto na Figura 15-a, intensificaram a ação das trincas, agindo como pontos de concentração de tensão e sendo determinantes para este resultado. 
O corpo de prova C (Figura 15-c), entretanto, apresentou uma reação diferente dos demais, onde o fenômeno abertura em "jacaré" pôde ser observado. Este fato, está associado a concentração de tensão compressivas na região mediana do corpo que, ao chegarem no máximo, rompe, aliviando as tensões.

\subsection{Ensaio de dureza}

Os resultados de dureza encontrados para a liga de alumínio ASTM 6262E T6 antes e depois da laminação seguem a ordem apresentada na Tabela 7.

Tabela 7: Resultados de dureza do alumínio.

\begin{tabular}{cccc}
\hline Corpo de prova laminado & Dureza inicial & Dureza final [HRB] & Aumento [\%] \\
\hline Em dois passes & & & \\
1 & 56,5 & 65,8 & $16 \%$ \\
2 & 59,0 & 69,3 & $17 \%$ \\
3 & 56,0 & 68,8 & $23 \%$ \\
4 & 59,0 & 70,0 & $19 \%$ \\
5 & 58,0 & 68,5 & $18 \%$ \\
Média & 57,7 & 68,45 & $19 \%$ \\
Em um passe & & & \\
6 & 57,5 & 68,5 & $19 \%$ \\
7 & 58,5 & 70,0 & $20 \%$ \\
8 & 53,0 & 70,8 & $33 \%$ \\
9 & 55,0 & 72,0 & $31 \%$ \\
10 & 57,0 & 70,8 & $24 \%$ \\
Média & 56,2 & 70,4 & $25 \%$ \\
\hline
\end{tabular}

Nota-se que, conforme os resultados apresentados na Tabela 7, que houve, em média, um aumento de $19 \%$ na dureza dos corpos laminados em duas etapas e um aumento de $25 \%$ para os corpos laminados em uma etapa.

Estes resultados sugerem que os corpos laminados em uma etapa obtiveram em média $6 \%$ a mais de melhora na dureza, porém, conforme estudos bibliográficos sobre o tema, tal condição não deveria ser atingida, tendo em vista que a deformação final nas duas condições de laminação é igual. Portanto, entende-se que as diferenças encontradas se estendem a soma dos erros possíveis do ensaio.

Os resultados de dureza encontrados para a liga de latão ASTM-B-16 C360 com têmpera 1/2 duro antes e depois da laminação seguem conforme a Tabela 8 .

Tabela 8: Resultados de dureza do latão.

\begin{tabular}{cccc}
\hline Corpo de prova & Dureza inicial & Dureza final [HRB] & Aumento [\%] \\
\hline Em dois passes & & & \\
1 & 74,5 & 84,0 & $13 \%$ \\
2 & 75,0 & 85,3 & $14 \%$ \\
3 & 74,0 & 87,8 & $19 \%$ \\
4 & 76,0 & 85,3 & $12 \%$ \\
5 & 75,0 & 86,0 & $15 \%$ \\
Média & 74,9 & 85,7 & $14 \%$ \\
\hline
\end{tabular}

Nota-se que, conforme os resultados apresentados na Tabela 8 , houve, em média, um aumento de $14 \%$ na dureza nos corpos após a laminação.

\subsection{Ensaio de rugosidade}

A Tabela 9 apresenta os resultados de rugosidade para a liga ASTM 6262E T6. 
Tabela 9: Resultados de rugosidade do alumínio.

Corpo de prova

Rugosidade como usinado Rugosidade como laminado

Diminuição [\%]

Em dois passes

$\begin{array}{cccc}1 & 0,735 & 0,376 & 49 \% \\ 2 & 1,129 & 0,259 & 77 \% \\ 3 & 1,171 & 0,221 & 81 \% \\ 4 & 0,816 & 0,264 & 68 \% \\ 5 & 0,706 & 0,279 & 60 \% \\ \text { Média } & 0,911 & 0,2798 & 69 \% \\ \text { um passe } & & & \\ 6 & 0,796 & 0,209 & 74 \% \\ 7 & 0,922 & 0,307 & 67 \% \\ 8 & 0,447 & 0,315 & 30 \% \\ 9 & 0,663 & 0,302 & 54 \% \\ 10 & 1,424 & 0,223 & 84 \% \\ \text { Média } & 0,850 & 0,271 & 68 \%\end{array}$

Nota-se que, conforme os resultados apresentados na Tabela 9, houve, em média, uma diminuição de $69 \%$ na medida de rugosidade dos corpos laminados em duas etapas e uma diminuição de $68 \%$ para os corpos laminados em uma etapa.

Estes resultados se mostram bastante semelhantes, com uma diferença média de $1 \%$. A semelhança entre estas rugosidades já era esperada, tendo em vista que este valor está muito mais relacionado com a rugosidade dos rolos laminadores do que com a deformação do metal. Em outras palavras, um rolo mais rugoso resultará em peças mais rugosas, enquanto um rolo com menos rugosidade resultará em peças menos rugosas. A Figura 16 apresenta o perfil de rugosidade do corpo de prova número 10, escolhido por apresentar a maior variação nos resultados.

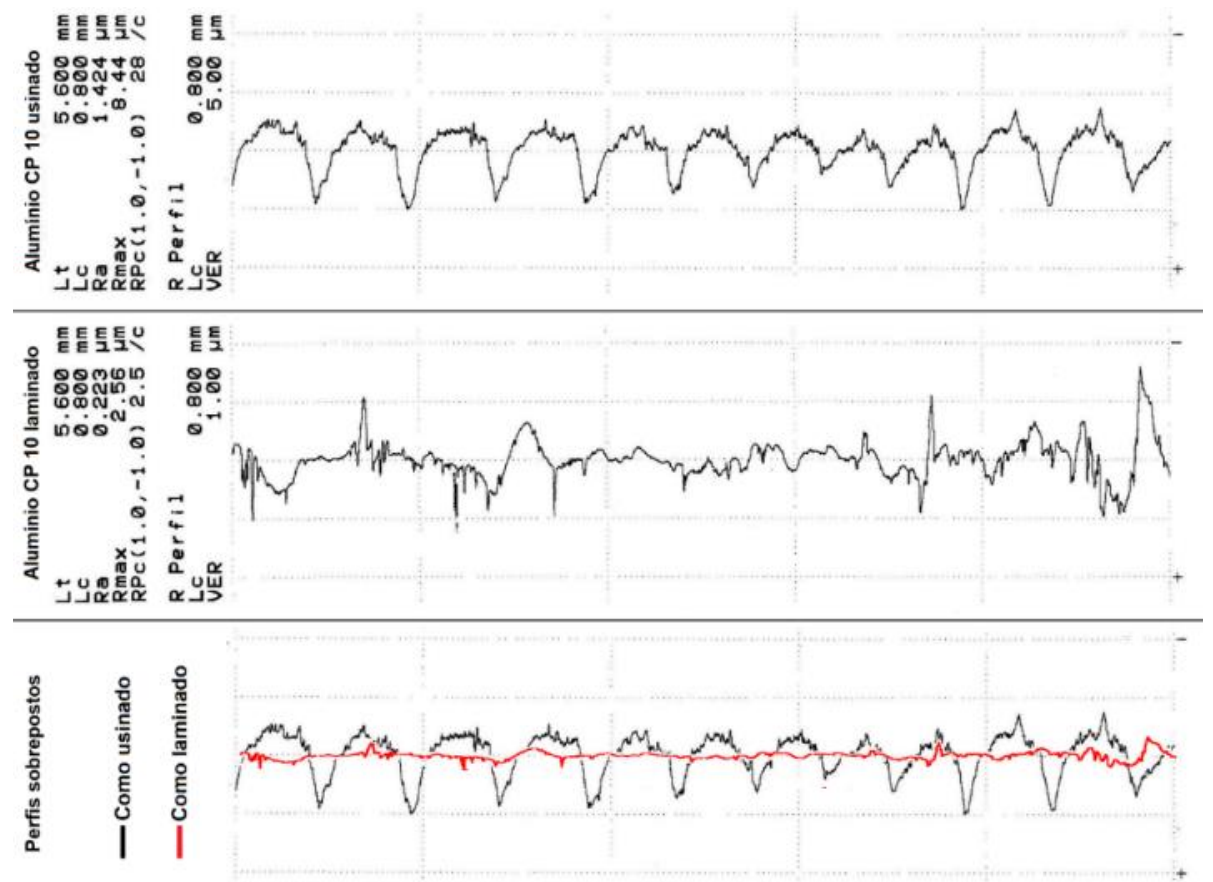

Figura 16: Perfil de rugosidade do CP 10 em alumínio.

Conforme o perfil de rugosidade do alumínio laminado (Figura 16), ficou bastante evidente o padrão imposto pelas marcas de usinagem, enquanto que no perfil laminado obteve-se picos mais acentuados. Com os perfis sobrepostos, em mesma escala, fica bastante evidente o resultado na melhora desta característica.

Os resultados de rugosidade encontrados para a liga de latão ASTM-B-16 C360 com têmpera 1/2 duro antes 
e depois da laminação seguem conforme a Tabela 10.

Tabela 10: Resultados de rugosidade do latão.

\begin{tabular}{cccc} 
Corpo de prova & Rugosidade como usinado & Rugosidade como laminado & Diminuição [\%] \\
\hline Em dois passes & & & $88 \%$ \\
1 & 1,901 & 0,227 & $61 \%$ \\
2 & 0,831 & 0,327 & $79 \%$ \\
3 & 0,831 & 0,174 & $85 \%$ \\
5 & 1,426 & 0,220 & $87 \%$ \\
Média & 2,207 & 0,279 & $83 \%$ \\
\hline
\end{tabular}

Nota-se que, conforme os resultados apresentados na Tabela 10, houve, em média, uma diminuição de $83 \%$ na medida de rugosidade dos corpos laminados. A Figura 17 apresenta o perfil de rugosidade do corpo de prova número 5 , escolhido por apresentar a maior diferença.

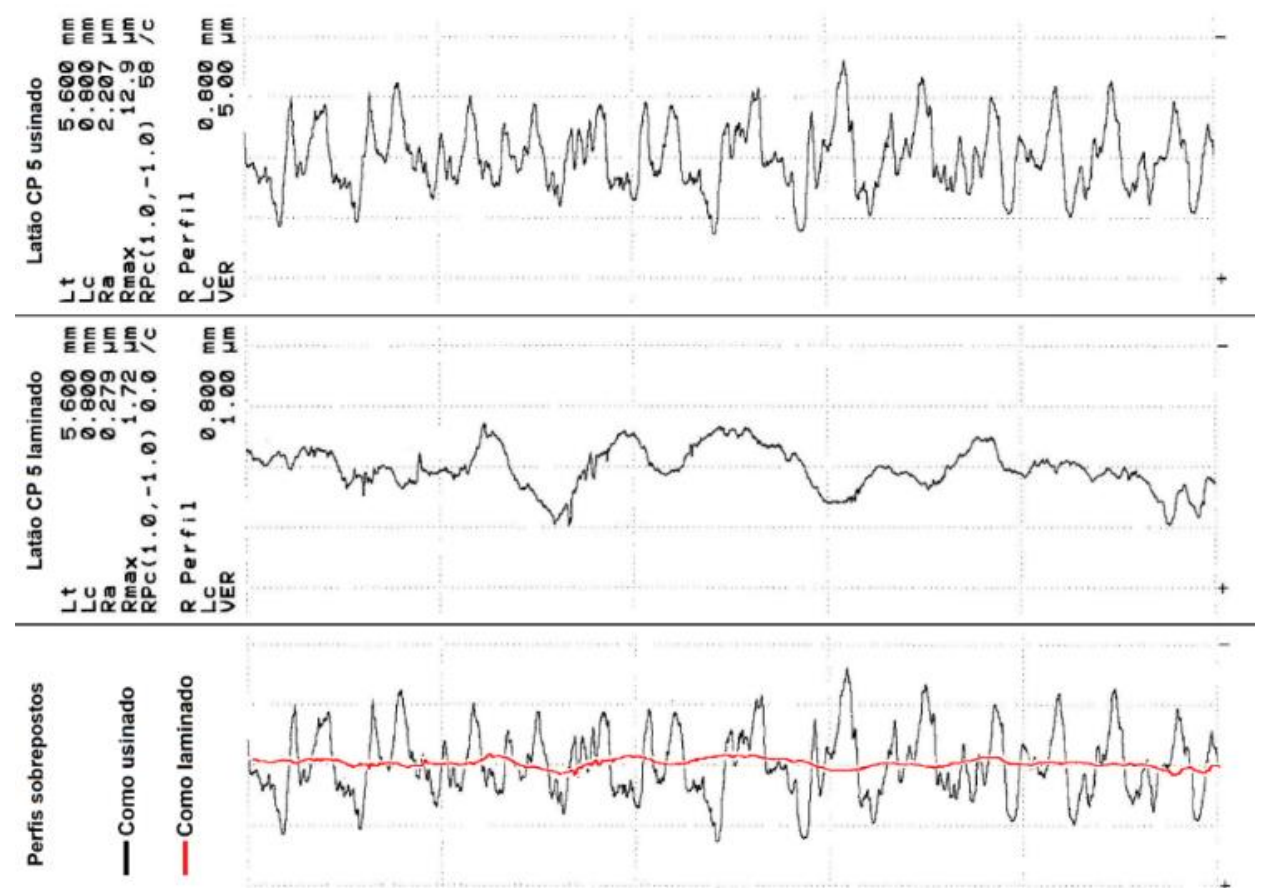

Figura 17: Perfil de rugosidade do CP 5 em latão.

De forma geral, nota-se que, conforme os resultados de rugosidade vistos na Tabela 9 e na Tabela 10, há uma variação significativa entre os valores de rugosidade inicial (como usinado) dos corpos de prova. Esta variação está relacionada a sua usinagem que, por terem sido construídos na fresa convencional, foi potencializada devido a variação de parâmetros de usinagem, principalmente quanto ao avanço de corte. Esta diferença é bastante visível, conforme exemplificado pela Figura 18. 


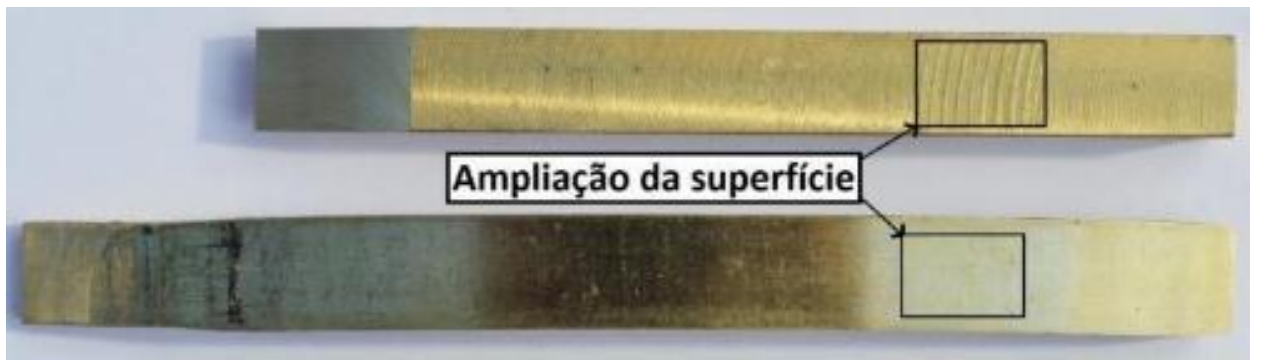

Figura 18: Rugosidade superficial.

Em contrapartida, conclui-se que, mesmo com valores de rugosidade distantes, se conseguiu resultados finais semelhantes, reforçando a hipótese de que na laminação haverá semelhança entre a rugosidade dos rolos laminadores e da peça laminada.

\subsection{Análise quanto ao funcionamento do laminador}

De acordo com o levantado no referencial teórico, o arco $(L)$ é o comprimento entre os pontos limites de contato entre o cilindro e a chapa. Entretanto, conforme dito por HELMAN [6], pode-se considerar para fins de cálculo a forma simplificada, a projeção horizontal AB em substituição do arco AC. Desta forma, considerando os cilindros laminadores com raio $(R)$ de $24 \mathrm{~mm}$ e a variação de espessura $(\Delta h)$ do $\mathrm{CP} 10$ de alumínio que foi de $1,70 \mathrm{~mm}$, chega-se ao valor de $L=6,39 \mathrm{~mm}$. Nestas condições, o comprimento real do arco de contato seria de $6,40 \mathrm{~mm}$, representando uma diferença de $0,15 \%$ entre os resultados obtidos pela equação simplificada e a real.

O cálculo do arco $(L)$ foi uma das variáveis utilizadas para realizar os comparativos entre os cálculos teóricos de potência de laminação propostos por SCHAEFFER [14] e HOSFORD [15] e as potências medidas através da diferença de corrente elétrica exigida pelo motor no momento da laminação, conforme equação da potência ativa descrita por COTRIM [12]. Para que os cálculos de potência obtidos se aproximassem tanto quanto o possível da realidade, considerou-se algumas das perdas envolvidas. Conforme sugerido por NIEMANN [11], estimou-se um rendimento de $96 \%$ para cada engrenagem cilíndrica helicoidal do equipamento, considerando as duas engrenagens, obtêm-se um rendimento de $92,16 \%$ para esta seção. Para o motoredutor e o motor foi utilizado o valor de $73,10 \%$ e $70 \%$, respectivamente, conforme dados técnicos dos fabricantes. Portanto, o rendimento total, considerando as características citadas, é de 47,16\%.

Referente as reduções de velocidade, apresentadas na metodologia deste trabalho, ao considerar a redução do motoredutor e a redução entre as engrenagens helicoidais, obtêm-se uma relação de 462 vezes. Desta forma, o motor com rotação nominal de 1720 RPM resulta em uma rotação final dos cilindros de 3,72 RPM. Ao considerar o torque nominal da caixa de redução frente a redução das engrenagens, tem-se um torque teórico máximo de 739,20 Nm. Nos experimentos, entretanto, o maior torque calculado foi para a redução dos corpos em alumínio em um único passe, alcançando um valor de $141 \mathrm{Nm}$. A Figura 19 mostra os valores de potência calculada e medida para os experimentos com os corpos de prova em alumínio.

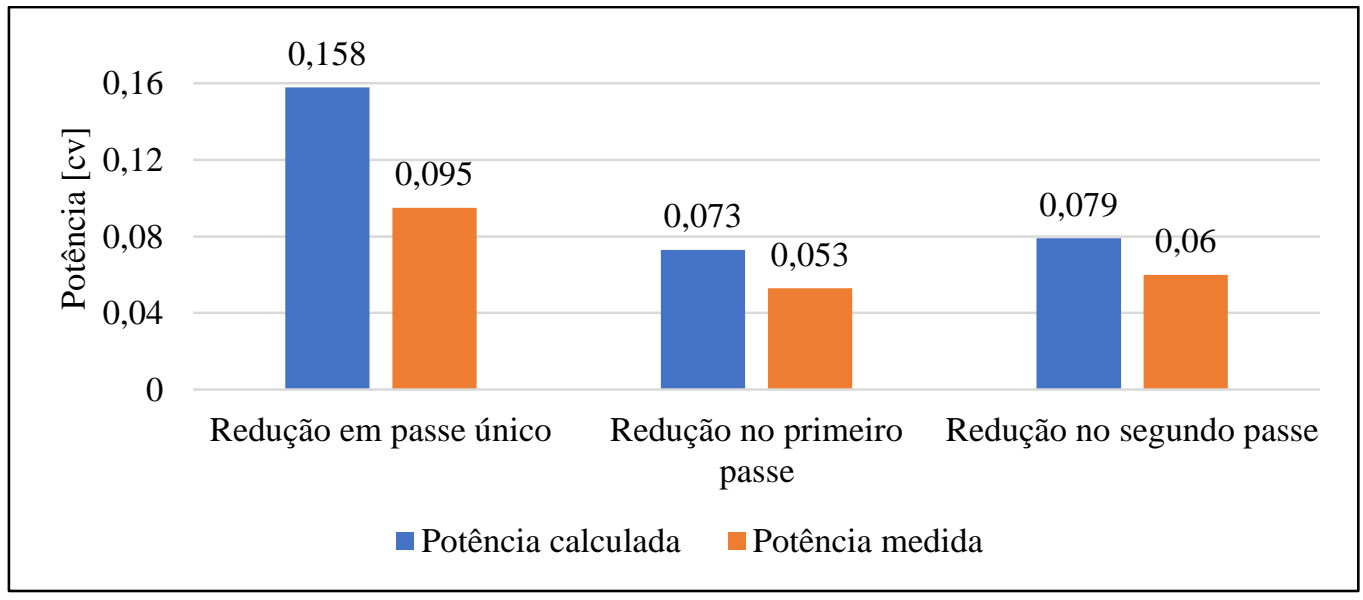

Figura 19: Resultados de potência para a laminação do alumínio.

Para todos os resultados mostrados na Figura 20, a potência calculada ficou maior do que a potência medida. Para a laminação um único passe, obteve-se a maior diferença, sendo esta de $40 \%$. Para a laminação em dois passes as diferenças foram menores, sendo de $28 \%$ para o primeiro passe e de $24 \%$ para o segundo. 
A Figura 20 demonstra os valores de potência calculada e medida para os experimentos com os corpos de prova em latão.

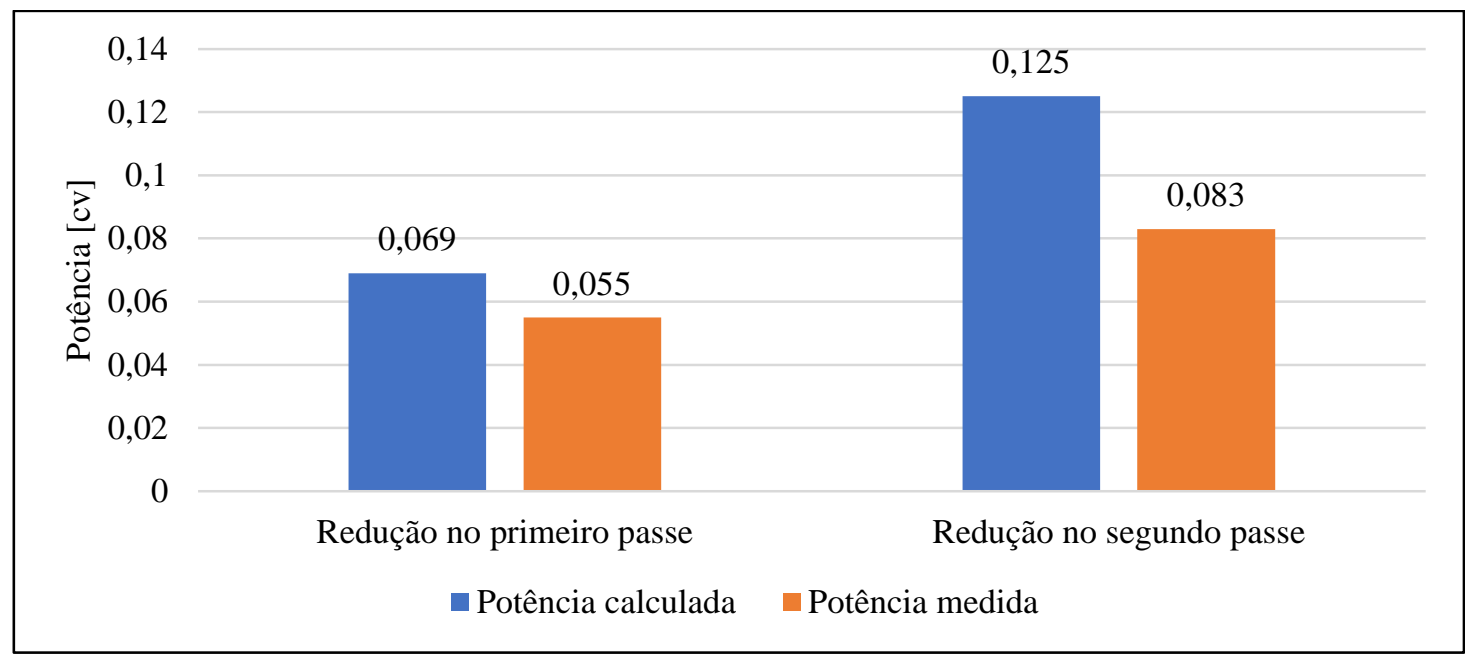

Figura 20: Resultados de potência para a laminação do latão.

Para os resultados apresentados, obteve-se, novamente, maiores valores de teóricos frente as potencias medidas. Para o primeiro passe a diferença foi de $20 \%$ para um torque teórico de $61 \mathrm{Nm}$, enquanto que para o segundo foi de $34 \%$ com um torque teórico de $111 \mathrm{Nm}$.

$\mathrm{O}$ aumento de potência exigido pelo segundo passe, para os dois materiais, se mostra maior que para o primeiro não apenas pelo o aumento na redução de espessura, mas pelo o encruamento sofrido pela etapa anterior. De forma geral, os valores medidos sugerem que o equipamento trabalhou com menores valores de energia. Este erro está associado a simplificação do cálculo, que não considera variáveis que possam influenciar neste resultado. Tal constatação é crítica para dimensionamentos de equipamentos de laminação através do método proposto e que exijam maiores potências, pois o valor de energia desperdiçado tende a ser igualmente maior.

\section{CONCLUSÃO}

Através do estudo reverso do equipamento de laminação proposto inicialmente, aliado a construção de um modelo tridimensional em software CAD que auxiliou a destacar as necessidades do projeto, foi possível construir um laminador elétrico didático de bancada que conseguisse realizar reduções significativas em processo de conformação a frio.

As deformações causadas nos corpos de prova foram significativas para um processo de laminação a frio, observando-se pequenas tolerâncias dimensionais em relação a espessura do material laminado, que se mantiveram bastante regulares em praticamente todas as laminações. Os corpos também apresentaram deformações em forma de flexão, causando o efeito similar de uma calandra. Tal efeito está associado ao demasiado encruamento e a falta de guias adequados na entrada e saída do material. Na indústria de laminação isto é sanado através da disposição de rolos em trens de laminação, onde se estabelece consecutivos passes sem perder o contato entre o rolo e o produto laminado.

As deformações causadas nos corpos de prova A, B e C foram interessantes do ponto de vista didático, pois proporcionaram o entendimento sobre as reações causadas por sucedias deformações a frio, que através do encruamento excessivo e o acumulo de tensões proporciona o rompimento do corpo.

A potência de laminação calculada pela equação proposta por Schaeffer e Hosford ficou acima das potências obtidas experimentalmente devido a inconsistência de algumas das diversas variáveis do processo. Entretanto, de forma geral, os resultados teóricos de potência foram bastante satisfatórios, pois encontram-se na mesma escala de grandeza dos resultados experimentais, podendo ser utilizados para um estudo inicial e de viabilidade de um processo futuro de laminação no equipamento.

Os resultados de dureza e rugosidade obtidos seguiram as características de conformação a frio estabelecidas pela bibliografia, apresentando significativas melhoras em ambos os casos. Se observou também que, em relação a rugosidade, os aspectos de superfície dos rolos de laminação são igualmente importantes para esta característica.

Com essa sequência de resultados obtidos nos diferentes aspectos estudados, chega-se à conclusão de que a adaptação do laminador proporcionou o estudo prático de diversos assuntos relacionados ao tema, podendo assim aproximar futuros acadêmicos a relacionar diversos assuntos que envolvem a conformação de metais por laminação. 
Para futuros trabalhos, sugere-se algumas melhorias do equipamento, como o desenvolvimento de um guia de laminação na entrada e na saída que resulte na laminação de um corpo plano ou ainda no desenvolvimento de um equipamento que utilize todo o torque teórico disponível através de mais rolos de laminação. Também podem ser realizadas análises experimentais mais detalhadas em relação aos materiais, trabalhando com laminações a quente e diferentes ligas metálicas. Sugere-se ainda o estudo de caracterização do material utilizado para o corpo de prova $\mathrm{C}$ em comparação ao corpo de prova $\mathrm{B}$ que, apesar de serem de materiais semelhantes, apresentaram resultados distintos.

\section{AGRADECIMENTOS}

Os autores gostariam de expressar sua gratidão à ajuda financeira da CAPES e ao CNPq.

\section{BIBLIOGRAFIA}

[1] NUNES, L.P., KREISCHER, A.T. "Introdução à metalurgia e aos materiais metálicos". Rio de Janeiro: Interciência, 376 p., 2010.

[2] DUFFÓ, G.S., FARINA, S.B., RODRÍGUEZ F.M.S. "Corrosion behaviour of non-ferrous metals embedded in mortar". Construction and Building Materials, v. 210, pp. 548-554, 2019.

[3] SCHAEFFER, L. "Conformação dos metais: metalurgia e mecânica". Porto Alegre: Rígel,108 p.,1995.

[4] KUN-SU K., SANG-HOON K., YUHYEONG J., et al., "Microstructural evolution of twin-roll-cast AleMn alloy during coldrolling and subsequent annealing: Effect of number of cold-rolling passes". Journal of Alloys and Compounds, v. 797, pp. 504-513, 2019.

[5] GONÇALVES, J.L., MELLO, J.D.B., COSTA, H.L. "Wear in cold rolling milling rolls: A methodological approach”. Wear, v. 426/427, pp. 1523-1535, 2019.

[6] HELMAN, H., CETLIN, P.R. "Fundamentos da conformação: mecânica dos metais". 2. ed. São Paulo: Artliber, p. 260, 2013.

[7] INSTITUTO AÇO BRASIL. Indicadores de mercado: estatísticas de desempenho. 2018. Disponível em: <http://www.acobrasil.org.br/site2015/estatisticas.asp>. Acesso em: 12 nov. 2018.

[8] ANDRADE, M.L.F., MASSABNI, V.G. "O desenvolvimento de atividades práticas na escola: um desafio para os professores de ciências". Ciência \& Educação (bauru), Campinas, v. 17, n. 4, pp. 835-854, 2011.

[9] SCHAEFFER, L. "Conformação Mecânica". 3. ed. Porto Alegre: Imprensa Livre, p. 167, 2009.

[10] SOUZA, S.A. "Ensaios mecânicos de materiais metálicos: Fundamentos teóricos e práticos". 5. ed. São Paulo: Edgard Blucher, p., 286, 1982.

[11] NIEMANN, G. "Elementos de máquinas: cálculo, diseño y construcción”. 2. ed. Barcelona: Labor, p. $786,1973$.

[12] COTRIM, A. A.M.B. "Instalações elétricas". 5. ed. São Paulo: Pearson Education do Brasil, 496 p., 2009.

[13] WEG. W22 IR2 0.5 cv 4P 71 3F 220/380 V 60 Hz IC411 - TFVE - B3D. 2018. Disponível em: https://www.weg.net/catalog/weg/BR/pt/Motores-Elétricos/Trifásico-Baixa-Tensão/Uso-Geral/W22/W22-

IR2/W22-IR2-0-5-cv-4P-71-3F-220-380-V-60-Hz-IC411-TFVE-B3D/p/11385077>. Acesso em: 10 jul. 2018.

[14] SCHAEFFER, L., ROCHA, A.S. "Conformação mecânica: cálculos aplicados em processos de fabricação". Porto Alegre: Imprensa Livre, p. 243, 2007.

[15] HOSFORD, W.F., CADDELL, R.M. "Metal Forming: mechanics and metallurgy". 3. ed. Cambridge: Cambridge University Press, p. 312, 2007.

[16] PENG, H., DACHUAN, L.,YU WANG, et al., "Design of manufacturable fiber path for variablestiffness panels based on lamination parameters". Composite Structures, v. 219, pp. 158-169, 2019.

[17] ABM (São Paulo). Associação Brasileira de Metais. "Laminação e Calibração de Produtos Não-Planos de Aço". 4. ed. São Paulo: Édile, p. 614, 1987.

[18] HAI LI, PENG CHEN, ZHIXIU WANG, et al., "Tensile properties, microstructures and fracture behaviors of an $\mathrm{Al}-\mathrm{Zn}-\mathrm{Mg}-\mathrm{Cu}$ alloy during ageing after solution treating and cold-rolling". Materials Science and Engineering: A, v.. 742, pp.798-812, 2019.

ORCID

Mateus Willian Da Rosa $\quad$ https://orcid.org/0000-0002-1319-8007 
Cláudia Trindade Oliveira Fernando Dal Pont Morisso Sandra Raquel Kunst Jane Zoppas Ferreira Josimar Souza Rosa https://orcid.org/0000-0002-4472-5359

https://orcid.org/0000-0002-9653-9857

http://orcid.org/0000-0002-8060-3981

https://orcid.org/0000-0002-3137-297X

http://orcid.org/0000-0002-9663-6438 